\title{
Los estudios de género en la UBA y la UNAM: una conquista del feminismo académico
}

\section{Resumen}

Este artículo indaga los orígenes de dos espacios universitarios dedicados a los estudios de género en Latinoamérica: el Instituto Interdisciplinario en Estudios de Género en la Universidad de Buenos Aires y el Centro de Investigaciones y Estudios de Género en la Universidad Nacional Autónoma de México. Su surgimiento y consolidación evidencian la influencia de las demandas del movimiento feminista en la educación superior y las formas en que las académicas articularon esfuerzos para exigir la institucionalización de dichos espacios. Para ello, se rastrearon las acciones de las principales artífices, así como las repercusiones que han tenido estos espacios en el quehacer universitario de ambas instituciones.

Palabras clave: Estudios de Género; Educación superior; Feminismo; Argentina; México.

\section{Abstract}

This article explores the origins of two institutes devoted to Gender Studies in Latin America: The Interdisciplinary Institute of Gender Studies at the University of Buenos Aires and The Center of Gender Studies and Research at the Nacional Autonomous University of Mexico. Its emergence and consolidation demonstrate the influence of the feminist movement in higher education and the ways in which academics articulated efforts to demand the institutionalization of these spaces. For this, the actions of the main architects of these initiatives were traced, as well as the repercussions that both institutions have had in their universities.

Keywords: Gender Studies; Higher Education; Feminism; Argentina; Mexico.

Agradezco profundamente a las académicas de la UBA y la UNAM que brindaron su testimonio para la escritura del artículo, particularmente a la Dra. Araceli Mingo quien aportó datos relevantes para comprender la historia del CIEG, a la Dra. Andrea Andújar por sus comentarios y a Gabriela Mitidieri por facilitarme los testimonios grabados.

POR GABRIELA LOZANO RUBELLO. Licenciada en ciencias de la comunicación por la UNAM. Maestra en Estudios de la Mujer por la UAM-Xochimilco y doctoranda en Estudios de Género por la UBA. Líneas de investigación: género, educación superior, movimientos sociales. gabriela.lozano.rubello@gmail.com 


\section{Resumo}

Este artigo explora as origens de dois espaços universitários dedicados a Estudos de Gênero na América Latina: o Instituto Interdisciplinar de Estudos de Gênero na Universidade de Buenos Aires e do Centro de Investigação e Estudos de Gênero da Universidade Nacional Autônoma do México. Seu surgimento e consolidação demonstram a influência das demandas do movimento feminista no ensino superior e as formas pelas quais os acadêmicos articulam esforços para exigir que as universidades institucionalizem esses espaços. Para isso, foram traçadas as ações dos principais arquitetos, bem como as repercussões que esses espaços tiveram no trabalho universitário de ambas as instituições.

Palavras chave: Educação Superior; Estudos de Gênero; Feminismo; Argentina; México. 


\section{Introducción}

Los estudios de la mujer, Women's Studies o Etudes Fémenines, surgieron en Estados Unidos, Reino Unido, Italia y Francia durante las décadas del sesenta y setenta del siglo XX con el impulso de académicas, muchas de ellas historiadoras, vinculadas con el movimiento feminista que se dieron a la tarea de "investigar críticamente y reconceptualizar el conocimiento existente sobre las mujeres, así como las maneras en que el mismo ha sido construido y transmitido" (Bonder, 1984:28). Es así que este campo de estudio tiene diversos orígenes, pero uno de los más antiguos es la corriente intelectual denominada historia de las mujeres, la cual ha registrado la vida de mujeres europeas sobresalientes en distintos periodos de la historia. ${ }^{1}$ En cuanto a su objeto de estudio, este campo no sólo consideró que la inclusión de las mujeres en la historia era necesaria, sino también se interesó en observar los roles sexuales y el simbolismo sexual en diferentes sociedades y periodos para conocer su organización y cómo se mantenía el orden social (Zemon Davis, 1976).

Una década después, en los ochenta, se desarrollaron los estudios de género o Gender Studies entre académicas anglosajonas también vinculadas al feminismo y tiene entre sus antecedentes El segundo sexo de Simone de Beauvoir. Este campo de estudio adoptó el concepto de género como categoría de análisis para referirse a los procesos históricos de diferenciación entre los hombres y las mujeres, y analiza los múltiples aspectos de la experiencia humana para mostrar que está atravesada por relaciones de poder y otras variables como la etnia y la clase social (Scott,1996). Lejos de las argumentaciones deterministas, esta perspectiva explora el sistema de relaciones entre los sexos, éste entendido como la construcción simbólica establecida sobre la diferencia sexual (Lamas, 1996).

En Latinoamérica, hacia finales de la década de los setenta, ya se advertía una importante producción intelectual del movimiento feminista que impulsó el surgimiento de los dos campos de estudio ya mencionados en la educación superior, en los que México y Argentina fueron pioneros. La primera cátedra sobre el estudio de las mujeres en México se impartió en 1970 en la Facultad de Ciencias Políticas y Sociales de la UNAM. A ésta le siguió el Programa de la Mujer que nació en 1982 en la Universidad Autónoma Metropolitana- Xochimilco y, posteriormente en 1983, surgió el Programa Interdisciplinario de Estudios de la Mujer (PIEM) en el Colegio de México (Nieto y Estudillo, 2016; Urrutia, 2002).

En Argentina, previo a la vuelta a la democracia, este tipo de investigación se realizaba principalmente en centros privados ${ }^{2} \mathrm{y}$ organizaciones no gubernamentales (Blanco, 2018a). Al concluir la dictadura se lograron cambios sociales como la sanción de leyes que ampliaron los derechos de varones y mujeres, se promovieron nuevas prácticas políticas y se impulsó la democratización de las instituciones y de la vida cotidiana (Blanco y Vommaro, 2017; Barrancos, 2013). En este contexto, los estudios de la mujer y de género se desarrollaron en las universidades argentinas.

Con el objetivo de conocer el proceso de institucionalización de los estudios de género en dos de las principales universidades de Latinoamérica, este trabajo describe y compara el camino que recorrieron académicas de la Universidad de Buenos Aires (UBA) y la Universidad Nacional Autónoma de México (UNAM). Se eligieron estas universidades debido a que ambas cuentan con espacios dedicados a los estudios de género, desde los cuales se impulsa la creación, difusión e intercambio de conocimiento. El criterio que se consideró para la comparación entre la UNAM y la UBA es que son públicas y gratuitas, además de ser las mejor evaluadas de Latinoamérica (Chevalier Naranjo, 2019), lo que las ubica como centros de desarrollo de conocimiento central e innovador en la región. ${ }^{3}$

A casi tres décadas de su surgimiento, se busca conocer las consecuencias de la creación del Instituto Interdisciplinario en Estudios de Género (IIEGE) en la UBA y del Centro de Investigaciones y Estudios de Género (CIEG) en la UNAM para dar respuesta a las siguientes interrogantes: ¿̇en qué consistió la participación de las académicas en el proceso de consolidación de los espacios? ¿Cómo se dio el primer contacto entre ellas a pesar de que tenían orígenes disciplinares distintos? ¿La introducción de las demandas feministas y de la agenda de las mujeres en la discusión académica impulsó la creación de estos espacios?

Para el abordaje metodológico se apeló a la historia social y se recurrió a fuentes escritas y orales. Respecto a las primeras, se consultó bibliografía relativa 
al surgimiento de los estudios de la mujer y de género en Latinoamérica y materiales producidos por la UBA y la UNAM. En cuanto a las fuentes orales, se realizaron entrevistas entre los meses de octubre del 2018 a marzo del 2019 con trabajadoras del IIEGE y el CIEG y con académicas que ocuparon cargos de decisión en las universidades señaladas.

Una academia que plantea interrogantes: de los estudios de la mujer a la interdisciplina con perspectiva de género en la UBA

El espacio académico dedicado exclusivamente a los estudios de género en la UBA es el Instituto Interdisciplinario en Estudios de Género (IIEGE) que está ubicado en el cuarto piso de la Facultad de Filosofía y Letras (FFyL) en la ciudad de Buenos Aires. ${ }^{4}$

En cuanto a sus antecedentes, podemos rastrearlos en el seminario de posgrado "La construcción social del género sexual" que se impartió en la facultad de psicología de la UBA durante los años de 1985 y $1987,{ }^{5}$ así como la materia optativa "Introducción de los estudios de la mujer" que estaba a cargo de María Fernández (Blanco, 2018b; Bellucci, 2004; Barrancos, 2013). En 1987 se creó la carrera de especialización interdisciplinaria en estudios de la mujer en la misma facultad (Blanco, 2018a). A nivel nacional, las "Jornadas Nacionales de historia de las mujeres y de estudios de género" que se realizan desde 1991 cada dos años en diversas universidades nacionales, constituyen un espacio de intercambio para quienes escriben e investigan estos temas.

La primera cátedra sobre el estudio de las mujeres en México se impartió en 1970 en

la Facultad de Ciencias Politicas y Sociales de la UNAM. A ésta le siguió el Programa de la Mujer que nació en 1982 en la Universidad Autónoma MetropolitanaXochimilco y, posteriormente en 1983, surgió el Programa Interdisciplinario

de Estudios de la Mujer en el Colegio de México.
Diana Maffía señala otro recorrido en la FFyL de la UBA, cuando se realizaron una serie de semanarios que contaron con apoyo de María Lugones y llevaron a la consolidación de la Asociación de Mujeres en Filosofía. ${ }^{6}$ En 1989, dicha asociación organizó un congreso de filosofía feminista en el cual se planteó la creación de un centro de historia de las mujeres en la facultad, iniciativa que ya se discutía en diversas universidades nacionales, particularmente, por el impulso de la historiadora Reyna Pastor de Togneri. Fue entonces cuando un grupo de académicas, con el apoyo de Mirta Rosovsky quien se desempeñaba como secretaria del decano Luis Yanes, se dio a la tarea de buscar a profesoras y tesistas con trabajos en la línea de los estudios de la mujer y los estudios de género.

La primera convocatoria se llevó a cabo en la sala del Consejo Directivo de la FFyL y reunió a 50 personas que compartieron sus investigaciones. El Área Interdisciplinaria de Estudios de la Mujer (AIEM) se constituyó en julio de 1992 por Resolución 3571 del Consejo Directivo (AIEM, 1992) y el grupo inicial contó con profesoras de las carreras de Artes, Antropología, Educación, Filosofía, Historia, Lenguas Clásicas y Letras (IIEGE, 2019). Entre sus objetivos se encontraba el impulsar, promover y coordinar los estudios e investigaciones científicas sobre la mujer en cualquier época, así como la formación de recursos humanos (AIEM, 1992). Al recordar el proceso de consolidación de la AIEM, Maffía señala que fue importante el apoyo de parte de la autoridad de la facultad para la creación del área y de la revista Mora, pero la iniciativa también respondió a una demanda del feminismo académico local e internacional. Mirta Lobato, fundadora del AIEM, señala que el proyecto fue consecuencia de un "doble movimiento":

Por un lado, me parece que había algo que yo llamaría un movimiento desde abajo para decirlo de algún modo, que es toda una corriente intensa de producción de conocimientos en el área de historia de las mujeres que se venía desarrollando desde hacía mucho tiempo en caminos paralelos. También es cierto que responde a un movimiento más amplio, más global que se hacía en ese momento y hacía el principio de los noventa, una puede decir que hay una masa 
de conocimiento que hace posible que se piense en términos de creaciones institucionales que por ahí no estaban presentes en los momentos previos.

El movimiento más amplio al cual hace referencia Lobato es el que define a los estudios de género como un campo de estudio, lo que muestra que en la AIEM convergieron la tradición de la historiografía de registrar la participación de las mujeres y esta nueva corriente que define a las relaciones sociales como una construcción cultural de la diferencia sexual. Esto permitió la diversificación de los espacios de debate en el AIEM, ya que al encontrarse por vez primera con otras investigaciones, las académicas se vieron en la necesidad de poner a prueba sus conocimientos en campos que recién se exploraban en la universidad, ejercicio que advierten resultaba alentador y estimulante porque permitía plantear interrogantes que transgredían las fronteras de la propia disciplina.

Para organizarse como área interdisciplinaria, la AIEM contó con una coordinación grupal que tenía representantes por carrera, entre las que se encontraban, Ana Amado por artes, Mirta Barbieri por antropología, Margarita Roulet por filosofía, Marcela Nari y Susana Murphy por historia y Nora Domínguez por letras (IIEGE, 2019). Al principio, la articulación fue difícil porque las académicas no se conocían e, incluso, porque el decano se negó a que la representación del AIEM fuese grupal. Es necesario recordar que las primeras actividades del AIEM se vieron enmarcadas en un contexto social y político complejo en los años posteriores a la última dictadura cívico-militar. ${ }^{7}$ Respecto a lo que significó el trabajo emocional de recomponer los lazos dentro de la universidad, Lobato comentó:

Muchas pospusimos nuestras propias ideas sobre algunas cosas para lograr que el instituto fuera. El instituto fue preservado de conflictos políticos existentes en la facultad que podrían haberlo afectado de manera intensa, fue una política de resguardo, no salió porque sí.

Otras tensiones al inicio del AIEM fueron las señaladas por Nora Domínguez, quien comenta que las académicas buscaron medios para generar espacios de 
comunicación en un área que tenía que formar su propia agenda. En el proceso de encontrarse para discutir y conocerse, hubo quienes participaron en el área, pero no optaron por la continuidad porque primó lo disciplinar. La académica advierte que quienes se dedican a los estudios de género viven tensiones derivadas de la negociación permanente entre este campo y el diálogo con la propia disciplina.

Desde su institucionalización, el PUEG se destacó como un espacio de formación con perspectiva de género que reconoció las corrientes de pensamiento de la escuela feminista anglosajona y ha impartido talleres y capacitaciones para estudiantes $y$ trabajadores y trabajadoras de organismos del Estado, mujeres en situación de cárcel y para otras comunidades educativas.

Es así que en la formación de las académicas se advierten diversas escuelas y corrientes de pensamiento como la escuela de los Annales y el marxismo, pero en 1997 se advierte que los estudios de género ganan importancia. El 24 de junio de ese año, el AIEM cambió su nombre a Instituto Interdisciplinario de Estudios de Género (IIEGE, 2019). En cuanto a la transición que se evidencia en el cambio de nombre, Andrea Andújar, historiada del IIEGE, señala que no se planteó como un debate abierto como sucedió en otras academias. Por el contrario, señala que este hecho muestra que los intereses y objetivos se modifican en función de que la práctica del conocimiento es acumulativa y colectiva.

Actualmente, el IIEGE es el único instituto interdisciplinario de la FFyL y lo componen cerca de 150 personas y cuenta con reconocimiento nacional e internacional, y articula programas de posgrado con universidades de diversos países. ${ }^{8}$ Desde el 2012, la facultad que lo alberga emite el título de Doctorado en filosofía y letras en el área en estudios de género. actualmente el IIEGE. ${ }^{?}$ 
Del activismo a la institucionalización de los Estudios de Género en la UNAM

El espacio de la UNAM dedicado exclusivamente a la investigación en estudios de género es el Centro de Investigaciones y Estudios de Género (CIEG) ${ }^{10}$ que se encuentra ubicado en la Torre II de Humanidades de Ciudad Universitaria en la Ciudad de México. Para conocer el proceso de surgimiento de dicho espacio es necesario hablar de la experiencia del Grupo Autónomo de Mujeres Universitarias (GAMU).

Este fue un colectivo de académicas y estudiantes que se reunían periódicamente entre los años de 1979 a 1984 para realizar actividades como la lectura de textos feministas y la organización de grupos de discusión en diversos plantes universitarios. GAMU consideraba que las y los trabajadores y estudiantes de la universidad eran una pieza fundamental para la lucha feminista y socialista (Nieto y Estudillo, 2016; Murúa, 1996; Hierro, 2014). Su estructura consistía en núcleos autónomos cuyas representantes se reunían en un pleno para definir líneas de acción. Entre sus demandas se encontraba el derecho al trabajo, a la maternidad libre y voluntaria, a la socialización del trabajo doméstico, a la seguridad en el campus universitario y se enunciaban en contra de la orientación sexista y la discriminación en la educación (Murúa, 1996:35).

Hacia el fin del GAMU, ${ }^{11}$ algunas de sus integrantes consolidaron el Centro de Estudios de la Mujer en la Facultad de Psicología (CEM), el cual en diciembre de 1984 se convirtió en el primer espacio donde las académicas pudieron desarrollar investigación en el campo de los estudios de la mujer (Nieto y Estudillo, 2016; Murúa, 1996). Unos años más tarde se llevó a cabo el "Foro de académicas universitarias" cuyo objetivo fue concretar la formación de un espacio que diera servicio a toda la universidad. Dicho proyecto se sometió a discusión en 1990 durante un Congreso Universitario (CU). La propuesta presentada contó con las firmas de 36 académicas de diversas dependencias de la UNAM (CIEG, 2018). Las firmantes advertían que México estaba atestiguando importantes cambios sociales, económicos y culturales en la condición de las mujeres y que debido a esto, las relaciones entre los géneros mutaban, a la vez que surgía una nueva cultura que afianzaba los principios de igualdad entre los seres humanos.
Las palabras anteriores evidencian el interés colectivo que había por consolidar los estudios de género en el ámbito académico. Araceli Mingo recuerda que durante los años en los que se trabajó para concretar la institucionalización del espacio, las académicas desarrollaron diversas estrategias para que las autoridades escucharan la propuesta. En una ocasión, se convocó a un grupo numeroso de académicas que no formaban parte de la iniciativa original con el fin de mostrar mayor presencia. El acuerdo de creación del Programa Universitario de Estudios de Género (PUEG) se publicó el 2 de abril de 1992, en el rectorado del Doctor José Sarukhán.

La figura legal Programa facultó al PUEG para fungir como espacio de vinculación de la comunidad universitaria con otros actores de la sociedad, entre sus tareas estaba el impulsar la investigación, realizar actividades docentes y de extensión y el contar con una biblioteca y un programa editorial (CIEG, 2018). Entre las académicas que formaron parte del primer equipo de trabajo se encontraban Gloria Careaga, Araceli Mingo, Teresita de Barbieri, Lorenia Parada, Alicia Elena Pérez Duarte y Graciela Hierro. Con el tiempo, el PUEG ganó reconocimiento tanto al interior, como al exterior de la UNAM. Mingo enfatiza el valor que tiene dicha conquista, ya que el PUEG es el único espacio en la UNAM que surgió por iniciativa de la comunidad académica o "desde abajo", es decir, no por una instrucción de los órganos colegiados de la universidad. Sin embargo, el proceso también significó diversas tensiones. Una de las académicas fundadoras indicó: "Como institución tienes obstáculos (...) al impulsar casusas feministas que la gente no quiere ver, por ello es un movimiento profundamente desprestigiado porque pone en entredicho un orden y pagas el precio de eso." También mencionó que todo espacio que genera investigación tiene la necesidad de exigir a las autoridades el desarrollo de determinadas políticas, situación que siempre representa un conflicto.

Desde su institucionalización, el PUEG se destacó como un espacio de formación con perspectiva de género que reconoció las corrientes de pensamiento de la escuela feminista anglosajona ${ }^{12} \mathrm{y}$ ha impartido talleres y capacitaciones para estudiantes y trabajadores y trabajadoras de organismos del Estado, mujeres en situación de cárcel y para otras comunidades educativas. 
En enero de 2017, el PUEG modificó su nombre por el de Centro de Investigaciones y Estudios de Género (CIEG), un cambio que lo reconoce como espacio dedicado a la investigación de alto nivel académico, y cuyo objetivo es la transformación de las relaciones de género. En sus 27 años de trayectoria, sus académicas se han desempeñado como docentes en diversas dependencias universitarias y han participado en procesos relevantes para la UNAM como la creación de la Comisión Especial de Equidad de Género del Consejo Universitario y en la creación del Observatorio Nacional de Igualdad de Género en las Instituciones de Educación Superior.

\section{Conclusiones}

Al explorar la creación y consolidación del IIEGE y del CIEG se observan aspectos en común como el año de surgimiento, pero sin duda, el más relevante es que académicas de instituciones públicas y gratuitas lograron consolidar centros de desarrollo de conocimiento de vanguardia en los cruces de los estudios de género con diversas disciplinas. Esto confirma la potencialidad que tienen las instituciones públicas para articular y desarrollar conocimiento central y creativo en un contexto político que impulsa discursos liberales tanto en Argentina, como en México, que han pretendido ubicar a la educación privada como único referente del desarrollo e innovación. Otro aspecto en común es que los procesos de creación del IIEGE y el CIEG fueron consecuencia de un "doble movimiento" y "desde abajo". Por un lado, nacieron por iniciativa del impulso de las demandas del feminismo local y las trayectorias intelectuales de las propias académicas, así como por la influencia de un movimiento internacional que incursionó en las aulas de las dos universidades más importantes de Latinoamérica.

El feminismo académico de las mexicanas y argentinas promovió el intercambio que aró el camino para la institucionalización de estos espacios críticos y, una vez que lograron la formalización de los espacios, el aprendizaje que permitió que diversas líneas de investigación y orígenes disciplinares convergieran en un mismo campo de estudios fue una acción consciente. Tanto el AIEM e IIEGE, como el PUEG y posteriormente CIEG, se pensaron para ser espacios interdisciplinarios.
Es así que ante las preguntas de cuál fue la participación e intervención de las docentes en el proceso de consolidación del IIEGE y el CIEG y cómo se dio el contacto entre ellas a pesar de sus distintos orígenes disciplinares, podemos señalar que éstos surgieron de la organización de las académicas que advirtieron la necesidad de contar con un espacio formal para el estudio de dichas temáticas y que la inquietud local se retroalimentó del movimiento feminista cuya literatura transitó entre quienes tenían oportunidad de viajar a Europa o Estados Unidos, así como aquellas que volvían a la Argentina con inquietud de aportar al desarrollo de la academia nacional tras vivir en el exilio.

Por otro lado, quienes encontraron un campo fértil de investigación en el clivaje del género con otras áreas de estudio, también advirtieron tensiones a nivel personal. Por ejemplo, el dilema de dar prioridad a la construcción de una trayectoria en la propia disciplina o apuntar a la formación en género. Sin embargo, prevalece la idea de que el intercambio entre disciplinas es un terreno fértil que produce interrogantes que contribuyen al crecimiento de otros campos de estudio como los Queer y los estudios de las sexualidades, o profundizar las posibilidades de la historia social, la antropología y la filosofía, y que esto les ha permitido renovarse a sí mismas, explorar más allá de los límites de la propia disciplina.

Resulta evidente, entonces, que la práctica del conocimiento es acumulativa y que ambas instituciones son la materialización de distintos momentos de construcción colectiva en los cuales se plantearon cambios en las interrogantes y en los objetivos del conocimiento que buscaban producir las académicas. Por esta razón, la interdisciplinariedad hace del IIEGE y el CIEG enclaves para nuevas generaciones que exploran temáticas que cruzan las barreras de los campos de conocimiento tradicionales, lo que consolida a ambas instituciones como lugares activos y vigentes en la discusión y desarrollo de conocimiento tanto al interior de sus universidades como en el campo académico regional e internacional. Los temas y los perfiles de personas que han transitado por estas instituciones también son reflejo de la evolución que tuvieron los estudios de la mujer y los estudios de género en el mundo intelectual y académico de ambos países. 
Respecto a la pregunta de si la creación del IIEGE y el CIEG permitió la introducción de las demandas feministas y de la agenda de las mujeres en la discusión académica, las entrevistadas señalaron que hoy en día se analizan temas y metodologías originadas en el feminismo crítico y con perspectiva de género que antes no se consideraban en otras disciplinas. Una razón que se identifica, en específico, en la experiencia del IIEGE, es que una importante población de académicas formadas en este instituto ingresó a la carrera de investigación en el Consejo Nacional de Investigaciones Científicas y Técnicas (CONICET) y la proyección que tiene su trabajo revaloriza los aportes de los estudios de género. En el caso del CIEG, una de sus fortalezas es el desarrollo de investigación aplicado a la atención de problemas nacionales y del quehacer universitario. De igual manera, es una consecuencia de la militancia de las feministas universitarias que el IIEGE y del CIEG ha tenido una activa participación en la inclusión de contenidos en la carrera de grado y el posgrado y que hayan participado en la redacción e implementación de los protocolos de atención a la violencia de género que existen en ambas universidades, lo que a su vez, ha incitado otras formas de intervención de estos equipos interdisciplinarios que tienen como objetivo cambiar las relaciones sociales en la UBA y en la UNAM.
Notas

1. Zemon Davis (1976) hace un recorrido historiográfico sobre los trabajos más relevantes dentro del campo de la Historia de las Mujeres.

2. Barrancos (2013:223)menciona en particular el Centro de Estudios del Estado y la Sociedad (CEDES).

3. En cuanto a la importancia que tienen en sus propios países, cabe señalar que la UNAM ocupa el primer lugar en número de estudiantes, docentes e investigadores del Sistema Nacional de Investigadores (SNI), así como de número de revistas indexadas en México (ecum, 2019). Por su parte, la uba concentra el 25\% de los docentes categoría I de la Argentina y en sus institutos y facultades trabaja el $26 \%$ del total de investigadores que tienen cargo docente en una universidad nacional (Bekerman, 2018:259).

4. Existen también otros espacios en la UBA que cuentan con al menos un área de investigación vinculada a los estudios de género, como sucede en el Instituto Gino Germani de la Facultad de Ciencias Sociales.

5. Este espacio fue iniciativa de las psicólogas Gloria Bonder, Cristina Zurutuza y la psicoanalista Irene Meler (Blanco, 2018a).

6. Académicas en el ámbito de la filosofía ya difundían trabajos originales o traducidos dedicados a mostrar el sesgo sexista que tenía la producción filosófica del momento en la revista Hiparquia, publicada entre 1988 y 1999 (Femenías, 2005).

7. Para conocer los recorridos realizados por los feminismos académicos en la Argentina a partir de la recuperación de la democracia en diciembre de 1983, se recomienda la lectura de Feminías (2005).

8. Investigadores tesistas y becarios/as de la UBA, CONICET y de la Agencia Nacional de Promoción Científica y Técnica (ANPCYT), así como personal técnico y administrativo.

9. El ALFA Miseal fue un proyecto impulsado por la Unión Europea en el cual participaron 16 universidades. Uno de sus objetivos fue articular un posgrado internacional y el programa piloto se planteó para 5 años. La FFyL es una de las sedes con espacio de trabajo en el IIEGE.

10. Existen otras áreas en la UNAm que trabajan temáticas que se enmarcan en los estudios de género o feministas, tal es el caso del Centro de Investigaciones Interdisciplinarias en Ciencias y Humanidades (сеIICH), el cual cuenta con un área de Investigación Feminista.

11. Una de las acciones más importante del GAMU fue activar una campaña contra la violencia que ayudó a denunciar por vez primera las agresiones y violaciones ocurridas en el campus universitario, así como el hostigamiento en las aulas (Nieto y Estudillo, 2016).

12.Por ejemplo, el colmex y la UAm mantienen espacios con nombres vinculados a los estudios de la mujer. 


\section{Bibliografía}

Barrancos, D. (2010) Mujeres en la sociedad argentina. Cinco siglos, Buenos Aires: Sudamericana, $2^{\text {a }}$ ed.

Barrancos, D. (2013) "Estudios de género y renovación de las ciencias sociales en argentina", Horizontes Sociológicos, Año 1, Núm. 1, Asociación Argentina de Sociología, pp.219-232.

Bekerman, F. (2018) "Distribución desigual de las capacidades de investigación en las ciencias sociales argentinas: una mirada relacional", Revista Iberoamericana de Ciencia, Tecnología y Sociedad -CTS, Vol. 13, Núm. 37, pp. 257-288.

Belasteguigoitia Rius, M. (Coord.) (2012) En la punta de la lengua. Al filo de la imagen. El pUeg a 20 años, México: unam.

Blanco, R. y Vommaro, P. (2017) "Otros caminos, otros destinos. Transformaciones en los espacios y prácticas cotidianas de participación juvenil en los años ochenta”, en Vommaro, P., Vázquez, M., Nuñez, P. y Blanco, R. (Comps.), Militancias juveniles en la Argentina democrática. Trayectorias, espacios y figuras de activismo, Buenos Aires: Ediciones Imago Mundi, pp. 1-28.

Blanco, R. (2018a) "Del fulgor al desencanto. Desafíos para el feminismo académico en la fugaz experiencia de la Carrera de Estudios de la Mujer (Universidad de Buenos Aires)", Revista Interdisciplinaria de Estudios de Género, Núm. 4, colmex.

Blanco, R. (2018b) “Viaje, biografía, conocimiento - Formación en el exterior de académicas argentinas y diversificación de los estudios de género", Cadernos pagu, Núm. 53, Universidade Estadual de Campinas.

Bonder, G. (1984) "Los Estudios de la Mujer y la Crítica Epistemológica a los Paradigmas de las Ciencias Humanas", Revistas Uniandes, Núm. 13, Universidad de los Andes, pp.27-38.

Chevalier Naranjo, S. (2019) "Las mejores universidades de América Latina", World Economic Forum.

CIEG (2018) "Antecedentes del CIEG. 25 años trabajando por la igualdad en la UnAm", Centro de Investigaciones y Estudios de Género, unAm.

ECUM (2019) Estudio Comparativo de las Universidades Mexicanas, Red de Investigadores sobre Educación Superior. Recuperado de: http://www.ecum.unam.mx.

Femenías, M.L. (2005) “El feminismo académico en Argentina”, Labrys. Estudos Feministas, Núm. 7, Brasilia.

Femenías, M.L. (2009) "Género y feminismo en América Latina", Revista Debate Feminista, Núm. 40, México: unam/Cieg, pp.42-74.

Hierro, G. (2014), "Casi veinte años de feminismo en la unam. Del Gamu al PUEG” en Gargallo F.; Martínez Dávila, R.; Olivares, C. (Coords.), Maestra, filósofa, feminista. Graciela Hierro: un homenaje, México: PUEG/UNAM.

Grammático, K. (2010) "La I Conferencia Mundial de la Mujer: México, 1975. Una aproximación histórica a las relaciones entre los organismos internacionales, los Estados latinoamericanos y los movimientos de mujeres y feminista" en Andújar, A. et al. (Comp.) Hilvanando historias: mujeres y politica en el pasado reciente latinoamericano. Buenos Aires: Luxemburg.

IIEGE (2019), Facultad de Filosofía y Letras/Universidad de Buenos Aires. Recuperado de: http://genero.institutos.filo.uba.ar/

Lamas, M. (2006) Feminismo. Transmisiones y retransmisiones, México: Taurus.

Lamas, M. (1996) (Comp.) El género: la construcción cultural de la diferencia sexual, México: PUEG.

Maffía, D. (2008) "Carrera de obstáculos: las mujeres en ciencia y tecnología”, La Habana.
Murúa, L. (1996) "La lucha tiene que prender como una llama apenas empieza... (Gamu)”, Revista FEM, Año 20, Núm. 163, México, pp.33-36.

Nieto, J.E. y Estudillo, J. (2016) "Historia del Centro de Estudios de la Mujer de la Facultad de Psicología (1984-1992): el origen de la institucionalización de la perspectiva de género en la UNAM" en Estudillo García, J. y Nieto Arizmendi, J.E. (Comp.) Feministas mexicanas del siglo XX: espacios y ámbitos de incidencia, México, UNAM/PUEG, pp.170-190.

Scott, J. W. (1996) "Una categoría útil para el análisis histórico” en Lamas, M. (Comp.) El género: la construcción cultural de la diferencia sexual, México: PUEG, pp. 265-302.

UNESCO (1998) "Declaración mundial sobre la educación superior en el siglo XXI: visión y acción”, Conferencia mundial sobre la educación superior. Recuperado de: http://www.unesco.org/education/ educprog/wche/declaration_spa.htm

Urrutia, E. (Coord.) (2002) Estudios sobre las mujeres y las relaciones de género en México: aportes desde diversas disciplinas, México, COLMEX.

Zemon Davis, N. (1979) "Women's History" in Transition: The European Case”, Feminist Studies, Vol. 3 Núm.3/4, pp. 83-103.

Entrevistas realizadas por la autora a académicas del IIEGE y del CIEG entre octubre 2018 y abril 2019. Las entrevistas a Diana Maffía, Mirta Lobato y Nora Domínguez, fundadoras del IIEGE, fueron realizadas y grabadas por Gabriela Mitidieri en 2017. El material es parte del archivo del IIEGE-UBA y se grabó con motivo de los 120 años de la FFyL-UBA. 